\title{
Feedback: understanding strategies and impact on EFL learning and teaching contexts ${ }^{1}$
}

\section{Re-alimentación: Comprensión de estrategias y su impacto en contextos de aprendizaje y enseñanza del Inglés como lengua extranjera}

\author{
David Felipe Espinosa Torres ${ }^{2}$ \\ Liceo Los Alcázares - Bogotá \\ juzt_danze@hotmail.com \\ Iván Camilo González Bejarano ${ }^{3}$ \\ American School Way language academy - Bogotá \\ halo2385@gmail.com \\ Juliana Moreno Restrepo ${ }^{4}$ \\ Gimnasio artístico de Suba - Bogotá \\ julianamorenorestrepo@yahoo.com
}

Received: September 30, 2016

Accepted: January 16, 2017

How to cite this article (APA, 6th ed.): Espinoza-Torres, D., González-Bejarano, I., and Moreno-Restrepo, J. (2017) Feedback: understanding strategies and impact on EFL learning and teaching contexts. Enletawa Journal, 10 (1), 43 - 65

1 Research Report

2 David Felipe Espinosa Torres is a Lecturer for the English and Bilingualism program at UniPanamericana and a homeroom English teacher at Liceo Los Alcázares primary school. He holds a bachelor's degree on Bilingual Education with an emphasis of English Language Teaching from Universidad El Bosque. Nowadays, he holds Master's Degree from the Master of Education with emphasis on English Didactics at Universidad Externado de Colombia. His areas of interest are: EFL learning blended learning, ICT's and feedback.

3 Iván Camilo González Bejarano holds a Bachelor degree in Bilingual Education with emphasis in English Language Teaching at Universidad El Bosque. Currently, he is teaching English and Spanish as a foreign language at the American School Way language academy. His research interests include: Feedback, EFL, Spanish as a foreign language.

4 Juliana Moreno Restrepo has a Bachelor's in Bilingual Education Degree with an emphasis in English Language Teaching from Universidad El Bosque. She is currently working at Gimnasio Artístico de Suba. Her research interests are: Feedback and EFL. 


\begin{abstract}
Feedback is a powerful tool that has significant influence on student success. Its meaningful impact on learning and teaching processes has been well-documented. However, there is minimal research concerning the impact of feedback strategies on foreign language learning. This article seeks to provide a theoretical and practical understanding of the impact of feedback on foreign language teaching and learning processes. This is done through a case study research conducted in a private institution in Bogotá, Colombia. The evidence demonstrates that the feedback strategies used and the manner in which they are administered influence their effectiveness. Three main strategies were observed and analyzed: corrective, motivational, and developmental. This article concludes with a suggestion to make feedback an explicit policy of teachers' education programs in the country.
\end{abstract}

Key words: Feedback, corrective feedback in EFL, motivational feedback, developmental feedback.

\title{
Resumen
}

La re-alimentación es una herramienta poderosa que tiene una influencia significativa en el éxito de los estudiantes. Esta influencia en los procesos de aprendizaje y de enseñanza han sido apropiadamente documentados, sin embargo existen muy pocas investigaciones con referencia al impacto que tienen diferentes estrategias de retroalimentación en el aprendizaje de una lenguaje extranjera. Este artículo busca proporcionar una contribución teórica y práctica dirigida al entendimiento del impacto que tiene la retroalimentación en los procesos de enseñanza y aprendizaje de una lengua extranjera en un estudio de caso conducido en una institución privada en Bogotá, Colombia. La evidencia reunida demuestra que el uso de estas estrategias de retroalimentación y la manera en que se proveen influyen en su efectividad. Tres principales estrategias fueron observadas y analizadas: Retroalimentación correctiva, emocional y de desarrollo. Esta investigación concluye con una sugerencia que indica la necesidad de la enseñanza de retroalimentación como una política explicita en programas educativos que forman maestros en el país.

Palabras clave: Re-alimentación, re-alimentación correctiva en inglés como lengua extranjera, re-alimentación motivacional, re-alimentación de desarrollo. 


\section{Introduction}

In every academic setting, feedback is required in order to help learners and teachers improve their performance. However, it has been observed that there is a lack of information regarding the positive impact of feedback strategies when used by teachers of English as a foreign language. This was observed in a Colombian educational setting where English language teachers are trained. In this research article, we will explain the lack of feedback information, how this case study was developed, and the results of the investigation. Furthermore, we will make suggestions on how to strengthen students' learning processes and motivation, as well as improving teaching effectiveness. Finally, this study will serve as a contribution to teaching and learning contexts where feedback is used as a learning improvement tool.

In order to better guide the reader, this article is divided in the following sections: First, research problem that entails the statement of the problem and rationale. Second, the literature review, which constructs are Exposure to a Foreign Language, Feedback, Negotiation and Selfassessment. Third, the methodology that covers the pedagogical intervention of the case study and finally, the results and conclusions of this qualitative case study and how they are proposed as an innovative way of closing the gap of information regarding the understanding of feedback strategies on an EFL environment.

\section{Research Problem}

\section{Statement of the problem}

It has been observed that there is a lack of well-provided feedback. This informal observation was substantiated by a needs analysis done through a written survey given to ten students of a private language learning institution located in Bogotá, Colombia. This is a well-known institution, with more than one thousand students across fourteen locations throughout Colombia. Those surveyed described their preference in receiving feedback in their native language rather than the target language. Also, teachers usually provide negative, rather than meaningful, feedback. As researchers, we decided to focus our study on feedback strategies provided in English. We also sought to find the impact which different meaningful and constructive strategies have on students learning English as a foreign language.

In addition, there is an information gap when it comes to student and teacher perspectives on feedback as a process. Because of this, we decided to apply a second survey where 20 students and 5 teachers had the chance to provide their personal points of view regarding feedback and its characteristics. On the one hand, the students' surveys indicated that students are aware that teachers constantly use feedback strategies, and that these strategies have a different impact depending on the task assigned by the teacher. On the other hand, the teachers' survey showed that educators account for their feedback strategies in an academic way. The teachers understood 
that feedback is part of the student/ teacher dynamic. They also believed that providing feedback in a foreign language may help improve their students' English level depending on their level of understanding. From the surveys, we concluded that students have a general idea of the definition of feedback and what it is used for. Additionally, teachers that were interviewed had broad knowledge of the different strategies they could use, and how feedback could positively be used to reinforce students' learning process.

Through the surveys, we also found that there was a lack of information that needed to be investigated. If feedback is essential for the learning process, how can English teachers effectively implement the use of feedback? Although teachers are interested in providing feedback by using different strategies, and students are interested in receiving it in order to improve, it is disconnected. Some aspects of feedback are failing, and the strategies used by teachers are not fully effective.

Indeed, it is observable that learners can reach proposed language goals, even when there is no formal feedback knowledge acquired. Generating feedback seems to be an unconscious strategy arising from the teachers' own resourcefulness. Nonetheless, the teachers seem unaware of the elements that compromise effective feedback or the theories and terminology of the feedback they employ.

For this reason, taking into account the necessities of the educational field and the importance of feedback as a tool in aiding students' English learning processes, the question which guided our study reads as follows: How do feedback strategies influence the processes of learning and teaching English as a foreign language? Additionally, the main research objective was to determine the impact of feedback strategies on the process of learning English as a foreign language at a private institution in Bogotá, Colombia.

\section{Rationale}

One of the most powerful influences on learning is feedback, and according to Hattie (2003), it is a holistic part of the educational process. Its level of effectiveness depends mainly on the way it is provided, hence, being able to understand this process could help identify issues in language production. Therefore, the aim of this research is to help students and teachers better comprehend the role of feedback strategies, as well as how to use the most effective feedback, which have been proven to yield positive results on the teaching and learning of English as a Foreign Language.

Teachers generally offer feedback based on the strategies that they trust in and feel most comfortable with. It is hoped that this article may help teachers to broaden their understanding of the importance and advantages of effective feedback and how it can contribute to improvement in their pedagogical practices and their students' language achievements.

Considering this, we hope this article nurtures not only this target community of teachers at the Language Academy where the study took place, but also aids 
other educational professionals who are providing feedback every day at schools, learning communities, and universities throughout Colombia.

\section{Literature Review}

Nowadays, there is a growing academic trendinidentifyingfeedbackasasignificant tool in the process of learning English as a foreign language. This phenomenon has been highlighted by authors such as Hattie and Timperly (2007), who observed that feedback is an important tool of the learning process in every educational atmosphere. Feedback, in this case, means any data (positive or negative) shared by any agent (e.g. teacher, parent, classmate, etc.) to a language learner in response to an instance of language production. It is our principal aim to discover and understand the shortcomings feedback strategies implemented by teachers may have, so that when theory is properly addressed, learning objectives in a foreign language can be fulfilled. To do this, we begin with a discussion on feed back strategies and the characteristics of effective application.

Feedback seems to be more effective when it provides information for correcting rather than highlighting the errors that students make. In fact, Hattie and Timperley (2007) also demonstrated that the power of feedback is determined by the strategies used after specific tasks are performed by learners. We have evidenced that apart from the feedback strategy used, this process encompasses two different parties: teachers and students.
As Bell and Orgnero (2011) explained, "teachers and students are participants in a reciprocal learning process" (p. 1). This is the reason why feedback seems to show an effective influence on the learning of a foreign language, since it is necessary for one agent to receive feedback and another to provide it.

Finally, as researchers, we believe that it is important to define which strategies teachers should use to improve feedback effectiveness as part of learning and teaching English as a foreign language. For this reason, we decided to focus this article on four areas of foreign language teaching and learning: Exposure to a foreign language, Feedback, Negotiation, and Self-assessment.

\section{Exposure to a foreign language}

For this study, it is relevant to explore the EFL field from the perspective of language as a fundamental part of human beings. To begin, Kumaravadivelu (1986) was one of the first authors to frame the English language within foreign language contexts. His studies, books and research articles have proposed many methods to explore, analyze and understand how EFL impacts learning and teaching purposes in the classroom. As proposed by Espinosa (2017), the work done by Kumaravadivelu made teaching and learning English for speakers of other languages (foreign context) known around the world.

A significant aspect of feedback to consider is when students are exposed to learning a foreign language through socialization in the classroom environment. 
Exposure can be taken as one of the most important conditions for L1 acquisition and this is equally related to foreign language (FL) learning. Thus, according to Wilkins (as cited in Ismail 1991) "if children are exposed to the L2 in the same way as they are exposed to the L1, greater success will be achieved" (p. 1). Therefore, learners will have a greater development in the classroom if they are completely exposed to the foreign language they are learning.

Presently, teachers tend to use more than one tool to achieve academic goals, and feedback is one of them. Feedback is also part of the exposure to a foreign language process. The results of feedback studies in foreign language environments have suggested that language perceptual patterns in feedback are modifiable according to the language in which they are given (Fledge, 1995). Furthermore, another research conducted by Ketsman (2012) exploredhow foreignlanguagepedagogical strategies are related to the expectations of both parties: teachers and students. This study concluded that expectations and other social factors shape foreign language processes and contribute to retention. Although teachers have different feedback strategies than their students, there seems to be a link in which these preferences align to achieve successful student performance in a foreign language. Corrective, motivational and developmental feedback are some of the feedback strategies teachers and students use in the process of teaching and learning a FL.

Even though there is a similar connection between L1 acquisition and FL learning processes, these two differ from one another. This acquisition/learning distinction is a fundamental hypothesis presented by Dulay, Burt and Krashen (1982), who propose that "adults have two distinct and independent ways of developing competence in a second language" (p. 138). Thus, components such as feedback, including exposure to the language, seem to affect language learning. Additionally, in FL learning, the learner may have the choice of whether or not, and to what extent they expose themselves to the taught language, while in L1 acquisition, exposure is automatic. On the other hand, the amount of exposure received by those who are learning the FL is far more limited than that received by children acquiring the L1. Students who are not immersed in a second language context have broad limitations regarding competence development in foreign language learning.

In sum, we argue that it is essential for learners to stay in contact with the FL as much as possible, because such exposure to the new language will reinforce their language learning process and production after receiving feedback.

\section{Feedback}

Feedback is a process that consists of information from a specific assessment task which is being "fed back" to the student and is a key element in assuring the effectiveness of formative assessment. Feedback has two basic functions: to tell students how well they have performed on the assessment task (including what a certain grade means) and to indicate how the outcome could have been improved 
(Sadler, 2010). In addition, Hatie and Timperley (2007) identified it as one of the most powerful influences on learning and achievement, noting that this influence can be either positive or negative. Even though feedback is one of the major influences in the learning process, the type of feedback, its impact and meaning, and the way it is given can alter the effect.

Furthermore, Hattie and Timperley (2007) established feedback as a cycle that is only useful when continuous. Feedback is a consequence of performance given by the teacher to assist the student's under-standing and to inform the student about their performance. The role of the student is to correct their performance and continually apply the feedback, yielding more feedback in future instances. However, this cycle can work in reverse and teachers can also receive feedback from students through different instruments: self-assessment, co-evaluation, hetero-evaluation and peer-feedback.

Students appear to be aware of the benefits of feedback, during and after it is provided, since it is the teachers' role to guide them in recognizing when feedback is given. Sadler (1989) identified three main necessary conditions for students to benefit from feedback:

(a) possess a concept of the standard (or goal, or reference level) being aimed for, (b) compare the actual (or current) level of performance with the standard, and (c) engage in appropriate action which leads to some closure of the gap (p.212).

This way, students receive, analyze, and comprehend feedback and its benefits so as to improve their future success in the practiced skill.

As well as focusing on the quality of the feedback messages, teachers should focus their efforts on strengthening the skills of self-assessment and peerassessment in their students (Yorke, 2003). This is how, according to Butler and Winne (1995), the formative assessment and feedback conceptual model works. In this model, an academic task is set by the teacher in class or as an assignment, which becomes the starting point for the feedback cycle. Hence, when the students engage with different activities, Nicol \& Macfarlane-Dick (2006) propose that it is "Engagement with the task requires that students draw on prior knowledge and motivation" (p. 202). In fact, when selfassessment processes come around, the students is in charge of managing their know way to build building through the guidance of the teacher.

In addition to the self-assessment model just mentioned, feedback can also be provided to encourage self-feedback and self-assessment. Students are always actively engaged in feedback processes, even when its provider is not the teacher or higher authority. In such processes, students first generate aspects of their own feedback as they monitor their performance, and later identify and correct any language mistake while carrying out the tasks. Following this, students interpret and filter feed back from external sources as Nicol \& Macfarlane-Dick (2006) propose. In fact, students are committed with the process of feedback, since they are allowed to create self-assessment environments. 
Feedback itself is not a fix-all solution, nor does it have an immediate impact. Rather, it is a powerful tool that needs to be part of a process, needs to be developed, and takes a certain amount of time to show successful results. Different aforementioned studies strongly and consistently show that feedback is more closely related to achievement than any other teaching process. It also works as a mechanism to improve learning in academic and behavioral fields. Therefore, it is beneficial for teachers and students to see the value of its impact on education, particularly foreign language learning because of its reliance on person to person interaction.

While we have been exploring feedback as a one-on-one process, feedback as a strategy may refer to any kind of information fed back to learners in an educational context. Thus, different authors have worked on two separate classes of corrective feedback: one-on-one feedback and intra-group feedback. One-on-one feedback is face-to-face feedback and is given immediately to the person who committed the mistake by someone other than the one who committed the mistake (Poulos and Mahony, 2008). Intra-group feedback is feedback that happens when individuals in a group provide feedback to the group and/or to one or more individuals within that same group (Böhm and Rockenbach, 2013). Therefore, corrective feedback has different characteristics connected with its application during our study.

To conclude, we propose that feedback seems to have a strong influence on academic achievement, and hence, plays a relevant role in contributing to students' learning development. To help and guide students, teachers have to make use of different feedback strategies to fulfill students' needs. The process of making feedback comprehensible is explored in the following section.

\section{Negotiation}

Negotiation is one of the factors that influences education and facilitates foreign language learning. Lyster (2002), defined negotiation in teacher-student relations as a set of conversational moves of reciprocal feedback that work toward mutual comprehension. Hyland (2006) stated that many English as a foreign language teachers feel that they must give substantial feedback to generate reactions within their students in order to help them improve their language use and interactions.

William and Burden (2009) indicated that within the classroom, there can be mediators, people who play an important role in enhancing a students' learning process by selecting and shaping the learning experiences presented. Hence, interaction with such mediators, usually parents, teachers or peers who possess different levels of skills or knowledge, often leads to effective learning. Mediation by these individuals in the learning process encourages learners to move on to the next stage of learning or understanding. Mediators should be viewed as more than merely knowledge providers - they are interpreters, selectors, and shapers of knowledge as well. 
Educators should aim to empower learners with the necessary abilities and knowledge to help them become selfdirected learners through the process of negotiation. In addition, learners' needs, willingness and affective status (e.g. confidence or anxiety) should be considered during the negotiation process. Negotiation should not be unidirectional with passive input of teacher to student knowledge or skills. Through negotiation and interaction between learners, the learning materials and tasks, and context and mediators, students can become active learners in co-constructing knowledge.

Jungmi (2003) states that, "The negotiation on interaction is a very important part of classrooms because it shows that learners could offer numerous opportunities to receivecomprehensibleinput, to produce appropriate output, and to receive feedback which could facilitate second language learning" (p. 206). Teachers provide feedback on students' errors whenever they believe it is necessary. In so doing, they use various methods that allow the communicative flow to continue. Thus, teachers are not obligated to choose when to use feedback. Instead, they might integrate negotiation and feedback during teacher-student interactions. In fact, one instrument of feedback that can help to avoid this negative impact of negotiation procedures is the rubric.

During negotiation procedures, neither the role of teacher nor the role of the student is considered more important. Hence, a partnership is created which bears out and optimizes payoff (Co-evaluation). In fact, the theory that has been exposed in regards the negotiation procedures is extensive and relevant for this study. Therefore, we believe that teachers provide the necessary tools, but students are also in charge of their self-assessment in the classroom. That is what we call a "negotiation procedure."

\section{Self-assessment}

Assessing students is one of most time-consuming processes in education. However, it is of paramount significance. This processisgenerally considered a determining factor of the classroom atmosphere where English as a foreign language takes place, since assessing requires patience and a great deal of conscious preparation from teachers and students. Furthermore, a substantial body of research shows that feedback leads to successful learning through teachers' assessments, self-assessment, peer assessment and the need of designing and implementing rubrics in this process. These kinds of studies demonstrate that feedback is directly related to the learning process, as measured by assessments.

Black and William (1998) studied data taken specifically from the classroom that provided important and relevant evidence of how feedback improves the learning process. They described that teachers provide feedback with the purpose of helping students recognize the next learning step. Boud (1995) studied selfassessment and its effect on feedback, while Sadler (1989) had already identified in his earlier work three main necessary conditions for learners to benefit from feedback in academic tasks: identifying how good performance is defined in a 
classroom, identifying how current performance relates to good performance, and how to act to close this gap.

Boud (2000), furthermore, explained that as well as improving the quality of feedback messages and processes, teachers should put in more effort on how to strengthen the skills of self-assessment in their students by providing the necessary tools. Additionally, Zimmerman (1989) demonstrated that learners who self-assess and peer-assess themselves are more effective learners. They are more persistent and confident achievers. Zimmerman identified that students who demonstrate strong control over their own learning become more effective in self-assessment, and less dependent on the teachers' support.

To summarize, these studies suggest that the use of appropriate feedback strategies by teachers can guide students to improve their learning process and results in the study of a foreign languagenamely, English. It can also be concluded that the more students are exposed to the foreign language, the better their results will be. Such exposure allows students to improve their foreign language learning process. In addition, the importance of reinforcing student self-assessment cannot be underestimated. Students have the ability to create their own learning strategies to achieve the objectives in the classroom environment. Finally, negotiation procedures between teachers and students must be strengthened to create a better learning environment.

Nicol and Macfarlane-Dick (2007) developed a study that explored feedback aspartofself-assessment processes.Intheir research, they proposed that "Feedback is involved when students actively control their study time or their interactions with others (behavior), and when they monitor and control motivational beliefs to adapt to the demands of the course (e.g. choosing a personal goal orientation)" (p. 205). We, as teacher-researchers, tend to assume that while learners can self-regulate and have good behavior; this does not mean that they always have full control of their learning process. Therefore, teachers should evaluate students' development and analyze the best strategies in which to provide feedback.

\section{Methodology}

The case study method is an empirical inquiry which investigates one phenomenon in a real context as stated by Yin (as cited in Zainal, 2007 p. 2). Such investigators, like Yin (1994), have explained that the point of using this tool is to have some measure of control over events when the object of study is a phenomenon that occurs within a real-life context. According to Yin (2012), a case study proposes three main steps in the research design:

1) it is necessary to define a case to study, 2) one must draw upon multiple sources of information which support the objectives of the article, 3) one must connect theories from different authors and studies in order to build a framework for understanding the case. In addition, Yin (2012) points out that a case study can take two different forms: a single case study in which only 
one person is analyzed, and a multiple case study in which more than two people are studied in the same way. This article will manage a multiple case study where the main objective is to collect and analyze data from several cases in order to obtain replicable conclusions.

Yin (2003) stated "A qualitative case study can be defined as an intensive, holistic description and analysis of a single entity, phenomenon or social unit" (p.41). Taking into account the previously cited definition, this article was designed to apply qualitative research by collecting, analyzing and triangulating the data collected through relevant instruments that include video tapes, paper surveys and in-depth-interviews. The data obtained was codified using the color coding theory and the grounded theory (Freeman, 1999). These theories were used to analyze aspects and patterns. The data was collected, grouped and sorted into three different research categories by following differences in patterns and similarities in ideas. Finally, the data analysis was conducted by a triangulation process, where the researchers started to intertwine these data excerpts in a way that it made it easier to understand by the reader.

Furthermore, the research took place at a private non-formal learning institute that has been accredited for the design and presentation of language learning services. This ensures that all the educational processes in question are up to the level with international standards of education and language use (taking into account the Common European Framework). Finally, the participants of this study were seven students, including teenagers and adults, from sixteen to forty years old, who had a B1 English level, and five teachers with C1 English level.

\section{Pedagogical Intervention}

In order to achieve the aims of this investigation, it was necessary to create and apply ten different non-authentic and printed lesson plans based on the task-based method proposed by Willis (1996). The pedagogical practice carried out was focused on how to provide learning environments where teachers and the students felt free to apply feedback strategies in each session. The private non-formal institution where this study took place does not hold an Institutional Educational Project (PEI). Therefore, the application of these lessons was based on the needs of this specific group who participated in the research, rather than a whole learning community. Each lesson contained an assessment and rubric which allowed the researcher to evaluate and improve the process.

As mentioned above, the main objective of this article is to determine the impact of feedback strategies on the process of learning English as a foreign language in a private institution in Bogotá, Colombia. Thus, the main research objective allowed the researchers to connect the research questions with the pedagogical intervention. This is because the lessons provided the necessary data to analyze the impact of the materials in a specific EFL classroom. For this reason, two main instructional objectives were proposed: (a) To elicit 
students' application of feedback processes in the EFL learning and (b) To create a suitable environment for the teacher to use feedback strategies when teaching English as a foreign language. These objectives were proposed by Tomlinson (2012), along with the materials development framework, which provides a guideline on how to successfully create and adapt materials for the learning and teaching of English Language.

In the following paragraphs, we will describe the ten designed and applied lessons, the main objective of each session, the role of the teacher and students, and finally, a brief description of the taskbased activity for each class:

The first applied lesson plan described a class where the teacher, in the role of facilitator, shared a piece of literature (The Gunpowder Plot Story) and students were asked to read it aloud and complete a written activity. In this way, researchers could note when the students made oral mistakes and how often the teacher provided feedback.

The second lesson plan described a reading activity where students worked on analyzing a tale by Edgar Allan Poe. The teacher was asked to provide feedback in different ways when students made mistakes, that is to say, the teacher had the option to use different feedback strategies.

The third lesson concerned the topic of bioethics and asked students to analyze different situations where the topic was reflected. They had to develop a critical argument on personal experiences in the
English language. Finally, students were asked to provide written feedback about the class and the impact of the activities.

The fourth lesson plan was focused on phonetics and how students reacted to this class and topic. The class was voicedrecorded in order to investigate students' language usage and teachers' feedback strategies.

The fifth lesson plan was based on listening and speaking skills. It asked students to analyze a song and how it linked to phonetic symbols. Students were voice-recorded throughout the class in order to analyze their pronunciation mistakes, and then provide one-on-one feedback.

The sixth lesson plan was based on reading comprehension, and the topic was "texting nowadays". Teachers were asked to provide personal and individual feedback by taking into account the students' reactions receiving the feedback.

The seventh lesson plan involved providing information about food habits to students and asking them to relate that information to their own lives. The feedback mechanism implemented was creative role-play, where students and teachers changed roles. After the activity, the students, who had been in charge of the class, would provide peer-feedback and feedback to the teacher after the activity took place. This allowed researchers to study student perceptions about how feedback was given by the teacher.

The eighth lesson plan involved descriptions of animals and nature. The teacher was asked to provide feedback 
as many times as possible, and to record his or her perceptions of the students' learning processes.

The ninth lesson plan was designed to strengthen writing and speaking skills on the topic of gerunds and the subject of the sentence. Students practiced singing a song along with their partners. They provided self-feedback and peerfeedback every time they failed on the pronunciation or grammar of the song.

The tenth and final lesson plan was based on writing and speaking about endangered species. Since this was the final lesson, the feedback implementation for this lesson involved recording the students' voices to measure pronunciation improvement in their oral language skill.

\section{Results and Findings}

Self-assessment, negotiation procedures, motivation, attitudes, the environment, expectations and relationships are factors which play a remarkable role in the process of providing feedback. However, the primary goal of this research article was to identify the main patterns related to feedback strategies implemented in the context of learning and teaching English as a foreign language, and to study how they affected students' language learning outcomes. The qualitative research approach and data analysis grounded theory recorded not only feedback patterns, but also the perception of these feedback patterns by students and teachers. As a matter of fact, after the triangulation process, the investigation revealed which interactions were high-quality and had im- proved the academic environment.

In our data set, we identified three different forms of feedback that positively affected outcomes. These forms, alongside a study describing their aspects, are the following: corrective feedback (Lightbrown and Spada, 2006), motivational feedback (Dörnyei and Cheng, 2007), and developmental feedback (Kraback, 2014).

In keeping with these theories of feedback, we constructed and reflected upon three different categories of analysis: corrective feedback as support in EFL oral performance tasks, motivational feedback as a tool for EFL reinforcement, and developmental feedback as beneficial (or not) in EFL learning. Within these categories the data collected was coded as follows: Video Recordings (VR), PaperSurveys (SV) and In-depth-interviews (INT), for the groups Student (ST), Teacher (T) and Interviewers (INTVR). For instance, (VR2ST5T1) can be decoded as Video Recording number 2, participant Student 5, and Teacher 1.

\section{Corrective feedback as support in EFL oral performance tasks}

The success of feedback seems to largely depend on the type of strategies teachers use, yet each teacher has his or her own feedback strategies to encourage students' learning processes. This inconsistency may be one reason why learning a foreign language is experienced differently in different classrooms. This might also be the reason why feedback strategies, which could aid in improving students' English language learning and performance, should be further studied and broadly 
adopted. One specific feedback strategy which seems to heighten the quality of language learning is corrective feedback.

In this respect, researchers observed students' receptivity to this type of feedback. For example, it was observed how teachers were able to implement this strategy and how it had both positive and particular impacts on students' oral production. This type of feedback was the most common of the patterns observed, and teachers consistently chose it as a strategy. In doing so, teachers could monitor students' learning processes by analyzing what mistakes were made and how students properly addressed them, as shown in the following excerpt:

ST 3: Ok the pizza and the coke, here you are.

ST7: There is a problem I don't know pizza

\section{T1: I don't like pizza}

ST7: I don't like pizza.

This type of feedback emerges at a bridging moment, appearing as a connection created by a teacher, (T1), on what a student, (ST7), wants to say and how it should be said. In this example, the teacher finds a way to make the student aware of the mistake produced and the need to correct it as soon as possible. In addition, the sample cited above represents the role of accurate production in student learning. As soon as the student was provided with feedback, it generated a positive impact. Students began the activity as a regular situation where they created a natural English conversational environment, and the teacher interfered whenever she believed it was necessary. For example, when the student used "I don't know pizza" instead of using the verb "to like" to express "I don't like pizza." The teacher provided feedback and correction as soon as the mistake was made. The teacher used one-on-one feedback, changing the intonation of the corrected form spoken back to the student. The student's facial expression in this exchange showed a positive reaction to the feedback while repeating the correct utterance. This demonstrates a principal of effective feedback: appropriate tone of voice can increase a student's participation and level of correct language production.

Observe the following case on the impact of corrective feedback on a student's learning:

T1: Yes? Why? Tell me.

ST5: Yes, 'cause young people are always texting. Ammm... I forgot how to say "utilizando".

T1: using.

ST5: Using that language of texting. (VR2ST5T1.)

In the exchange above, the student's ability to produce was blocked by the lack of vocabulary, which provided the opportunity for the teacher to give feedback. The teacher asked a question with the purpose of receiving an open answer: "T1: Why? Tell me", which generated the following mistake:"ST5:yes, 'cause young peopleare always texting. Ammm...I forgot how to 
say...utilizando." The student understood the relation between the structure of the sentence and how to relate it to the class; however, the student was forced to ask the teacher for the translation of an unknown English word. The teacher provided the correct word by using a non-aggressive tone of voice in order to lead the student in creating the proper construction. The student understood the translation, appeared to appreciate the positive intention of the teacher, and immediately incorporated the word into the statement produced.

Although students pay attention during English sessions and may participate in different activities, it is essential to recognize whether students' level of receptiveness continues to be high to this specific kind of feedback. Likewise, teachers who participated in this research article observed that while they applied many feedback strategies, it was clear that corrective feedback stood out as the most common during the analyzed sessions. For instance, the following data collected allowed the researchers (INTVR) to understand that the interview answers match up with the characteristics and aspects of corrective feedback (Loewen, 2012). Even though one teacher, (T3), has a deep-seated faith in the strategies used to teach English as a foreign language, it was clear that they unconsciously made use of corrective feedback strategies by expressing the idea that they want "to give the studentenough tools to correct the mistake" and to "show the mistake to the students."

INTVR: Ok, what type of feedback do you apply? I have some here: corrective feedback, motivational feedback, constructive feedback, intrinsic feedback or maybe you have your own one? Another one like eclectic?

T3: I think my feedback; my personal feedback has little bit of all.

INTVR: All of them?

T3: Yes, because you try to correct the mistake or show the mistake to the students.

Example: I am making a mistake all the time how can I improve it. The idea is to give the student enough tools to correct the mistake but because the person has to do it, it is because he or she wants to do it.

To conclude, participants in this study demonstrated positive reactions and receptivity to this feedback strategy by properly correcting the mistake and repeating what the teacher prompted. However, yielding successful results with this strategy depends directly on how the teacher takes advantage of using corrective feedback in English. Explicit repetitions along with a friendly, nonaggressive tone of voice are necessary for success. Thus, students making the error, as well as others listening, could analyze and understand the mistake and how to correct it. Therefore, corrective feedback is a fundamental foreign language teaching strategy, particularly when teaching oral language skills. 


\section{Motivational feedback as a tool for EFL reinforcement}

Thereisafeedbackstrategy thatdeserves distinctive treatment in the EFL learning process. Motivational feed-back by itself, when accurate, is a tool to create positive motivation in students in order to enhance language production. Consequently, the results that were gathered from the use of this feedback strategy suggests that this tool is being properly applied. While learning a foreign language, this feedback strategy generates high receptivity and positive reactions from students. This strategy is often used to lessen negative feedback with the purpose of improving students' self-esteem (Cohen, Steele and Ross, 1999).

When motivational feedback is provided without any strings attached, its outcome can be immediately observed. Motivational feedback emerged as one of the most remarkable patterns during the different sessions observed. This strategy highlights students' correct achievements and allows the students to recognize the achievements they did not attain.

In fact, teachers constantly used words such as "Good," "Nice," "Great," and their tone of voice regularly changed. It increased when exclaiming the correctness of students' production. This feedback strategy called the attention of the researchers because teachers facilitated environments of confidence, thereby, increasing students' courage to keep participating during different English sessions. Teachers who corroborated understood that students felt better and have greater self-esteem when they are corrected in a positive, motivational way. As a matter of fact, motivational feedback is generally seen as a positive strategy when learning English as a foreign language. This notion was reinforced by the students who made sure it was understood that they prefer motivational feedback, and by the teachers who truly believed in it and used it.

As such, the following excerpt allows us to understand the process of motivational feedback:

T2: Say -Tetero\| (putting the tongue in the alveolar ridge) put your tongue here.

$$
\text { ST3:-Tetero\| (She laughs) }
$$

T2: Exactly, really good! You see? What is this?

In the above dialogue, it can be seen that the teacher decided to provide feedback by using positive expressions that generated interest. Students were asked to pronounce the consonant " $\mathrm{T}$ " in English by pronouncing certain words such as "Tetero" and following instructions regarding the position of the tongue. The teacher explained the correct utterance of the letter " $\mathrm{T}$ " and how to properly apply it in English. Once the students committed to this task, the teacher followed their correct production with words such as "Exactly" and "Really Good" as part of the process of motivating the students. The teacher in this specific case maximized the impact of tone when saying "Exactly" and "Really good." As soon as the student replied with the correct use of the letter, the student 
felt free to continue with the accurate pronunciation of the production. The next excerpt corroborates and complements the above information by presenting a parallel experience.

INTVR: Ok, good, what type of feedback do you apply? I have some like motivational feedback, constructive feedback, realistic feedback, etc.

T3: It's pretty important to be realistic 'cause it is according to the topic the student is developing during the classes, also with motivational feedback it's pretty important because they feel better, they feel they can improve their mistakes right? You need to be very confident, very, I don't know the way you give the feedback in order for students to receive it in the correct way.

In this interview, a teacher (T3) points out their perspective in regard to motivational feedback. Thus, the answers led the researchers to confirm that the main aspects, like self-confidence, selfesteem, attitude and self-assessment, are essential parts of achieving goals in EFL learning processes. Therefore, motivational feedback is a complementary and beneficial tool when learning a foreign language.

In conclusion, teachers use motivational feedback to generate a positive impact and reinforce students' English production. The tone of voice, attitude of both parties (teacher and student), confidence, and even the type of exclamatory language used are factors which affect the outcome of motivational feedback in the classroom. If done well, it can generate increased self-confidence in language learning classrooms.

\section{Developmental feedback as beneficial (or not) in EFL learning}

Developmental feedback arises at a certain period of the educational process when a teacher supplies multiple alternatives for students to store, assimilate, and apply new and complex information. This type of feedback is crucial since it lends itself to present improvement and future success. Thus, failing to provide this type of feedback leads to a greater probability of unsuccessful language production in the future.

Therefore, understanding this type of feedback is necessary. Despite this, developmental feedback was the least used by teachers, perhaps because of it complexity. When it was used, most teachers did not seem to recognize what it was. However, developmental feedback generated effective results. Moreover, students and teachers seemed to feel comfortable with this type of feedback, seeing as it does not negatively affect the student who makes the mistake.

T2: Sometimes you have to picture something in your mind $b / / b / /$ $\mathrm{b} / / \mathrm{b} / / \mathrm{b} / / \mathrm{b} /$ (Laugh)

T2: You associate things and that's how you remember things in the 
future, so can you probably say "Tetero, tonto" is it clear Dani? Can you please pronounce this one (teacher makes a b with his hands)?

ST1: B/b/.

T2: B /b/ B /b/ as a "Bobo" and this one (teacher makes $\mathrm{P} / \mathrm{p} /$ with his hands).

ST1: P /p/.

T2: $\mathrm{P} / \mathrm{p} /$ and $\mathrm{T} / \mathrm{t} /$.

ST2: $\mathrm{T} / \mathrm{t} / \mathrm{P} / \mathrm{p} /$.

ST1: T/t/.

T2: That's the sound of /T/ T/ T/ is better. $/ \mathrm{P} / \mathrm{P} / \mathrm{P} /$. the exercise you have to continue working on, otherwise you will forget it. Is that clear? (VR4ST1-2T2.)

As demonstrated in the transcription above, this type of feedback leads students to successfully produce language. The teacher provides a specific explanation of the pronunciation of different letters in English. The teacher related these to familiar sounds and connected them to the students' own language, thereby enhancing their long-term memory of the sounds. Immediately after presenting the letter sounds in a positive way and relating them to familiar words in the students' native language, the next student followed the teacher's association by pronouncing the requestedletter. Theteacherexplicitlycalled on students to develop their capacity for long-term memory as part of their English language learning by providing specific developmental feedback: "You associate things and that's how you remember things in the future." You can also see here that the teacher gives alternatives, "Tetero, tonto."

Observe the response in the following dialogue in the interview and survey:

INTVR: What type of feedback do you apply?

T4: Well, I think that the type is motivational and-empowermental.

INTVR: So, can you please give me a broad explanation of this feedback.

T4: Well, the empowerment, that theory is about that you have to empower anyone in their own process. So they don't need to follow anyone to learn but with their own strategies they can achieve something, learning.

Notice in the excerpt above the teacher explained how they used "empowermental feedback" as a tool in their classes. However, "empowermental feedback" is not recognized academically as a theory of feedback. Yet, based upon the explanation given (and an observation of the teachers' strategies in class), it is accurate to say that what the instructor truly uses is a form of developmental feedback that strives to communicate important concepts. This enables students' self-development of the language.

But does this strategy work? Is developmental feedback beneficial? Surveys (Quest) given to learners (ST3) allowed 
the researchers to understand more about developmental feedback:

Quest7: What do you do after receiving such feedback?

ST3: I do my best effort to keep it in mind and practice what I was told.

Quest12: Have you used the feedback that has been given to you by your teacher for future activities? (Justify answer).

ST3: Yes, I had. Because I usually don't have class with the same teacher I ask the new teacher if I am doing it the right way. When my problem is about a word that is difficult to pronounce, in my way back home I repeat the word many times as I can.

This students' answer is typical of the responses to this survey. It confirms that feedback is effective. This is substantiated by information about developmental feedback, affirming that developmental feedback is both what they seek and effective. Hence, this student's answer represents the long-term positive effect that the teacher aspired to instill. This student has developed a new, meaningful strategy to achieve their goals following feedback.

In summary, even when teachers had vague knowledge of what developmental feedback was, they did make constant use of it. The information analyzed from teacher and student interviews revealed that both parties described the characteristics of developmental feedback and its aims. Notwithstanding, students did not have extensive knowledge about the background or theory of this strategy, and they were not aware of how it could positively affect their EFL learning processes. Consequently, although developmental feedback was not significantly demonstrated, it was not fully absent. Thus, its aims were aspired by instructors and learners alike. For this reason, we considered it a beneficial strategy for teachers to adopt in the classroom in order to improve EFL outcomes.

\section{Conclusions and Pedagogical Implications}

Bearing in mind that feedback is a powerful tool that has remarkable influence on success when learning a foreign language, weidentified three types of strategies used to achieve significant outcomes. These outcomes are supported by different factors such as context, age, attitudes, cognitive abilities, and level of proficiency in the FL These factors were noted, but not explicitly studied. Through observation of feedback and its impacts, we categorized these three feedback strategies as: corrective feedback as support in EFL oral performance tasks (Loewen, 2012), motivational feedback as a tool for EFL reinforcement (Dörnyei and Cheng, 2007), and developmental feedback as beneficial (or not) in EFL learning (Kraback, 2014). Although such strategies are necessary in the EFL learning processes, particularly for oral production, 
the impact on students depended directly on the chosen strategy that was applied by the teacher.

Corrective feedback was the main strategy used by teachers in this research. In addition, learners seemed highly receptive to this strategy. They showed positive reactions when receiving it, and they successfully corrected their mistakes after acknowledgingthem. Thiskind offeedback consistently produced appropriate use of English language, and it did not appear to have any kind of negative effect upon learners' production or confidence. This might be due to the manner in which feedback was provided by the teacher.

Likewise, teachers' feedback suggested that they employed many different strategies. However, recordings and observations revealed that not all of the teachers had a very high usage rate during EFL classes. However, affirmative words and phrases such as "exactly," "really good," "excellent," and "good," were frequently observed, which, along with the usage of an appropriate tone of voice, were an effective combination that heightened students' EFL learning processes. It can even be said that, based on the analysis of the findings, overuse of this strategy bears fruit with students' oral production.

Apart from the previous two strategies, developmental feedback was the least present in teacher's praxis, showing few interventions during the observation. Nevertheless, when applied, this strategy led to excellent outcomes (self-confidence, self-correction, empowerment). As re-searchers, we identified that both teach- ers and students felt utterly comfortable with developmental feedback due to the fact that neither teachers nor students were hampered or discouraged in their efforts to understand or correct mistakes.

The main result which emerges from this research is a necessity to provide deeper support to worthwhile educational strategies. By analyzing and comprehending the data produced by the research after two years, it is possible to conclude that feedback plays a significant role in EFL outcomes, and that the gap of information between teachers and students needs to be closed in order to make significant use of feedback strategies in the classroom. Thus, feedback is an effective and significant tool for teachers to use in EFL educational settings that engages both parties. It would be valuable to consider explicit instruction in feedback strategies (particularly developmental feedback) for the purpose of improving EFL teaching in the country. Despite the importance of feedback, it is not the only determining factor in EFL success: self-assessment, negotiation procedures, motivation, attitudes, environment, expectations, relationships, tone of voice, context, age, cognitive abilities and starting level of proficiency in the FL, also have a direct influence on the effectiveness of feedback when it is employed.

\section{References}

Bell, A. and Orgnero, C. (2011). Brainbased cognitive processes that underlie feedback between adult students 
and instructors. Proceedings of the Education Research Conference and Canadian Association for the Study of Adult Education Joint Meeting, Toronto, Ontario, Canada.

Black, P. and William, D. (1998). Assessment and classroom learning. Assessment in Education, 7-74.

Boksem, M., Van der Helden, J., and Blom, J. (2009). The Importance of Failure: Feedback Related Negativity Predicts Motor Learning Efficiency. Neuroimage, 47, S179.

Böhm, R. and Rockenbach, B. (2013). The inter-group comparison-intra-group cooperation hypothesis: comparisons between groups increase efficiency in public goods provision. PloS one, 8(2), e56152.

Boud, D. (1995). Enhancing learning through self-assessment, London: Kogan Page

Boud, D. (2000). Sustainable assessment: rethinking assessment for the learning society. Studies in Continuing Education. 22 (2), 151-167.

Butler, D. and Winne, P. (1995). Feedback and Self-Regulated Learning: A Theoretical Synthesis. Review of educational research, 65, 3245-281.

Cheng, H. and Dörnyei, Z. (2007). The use of motivational strategies in language instruction: The case of EFL teaching in Taiwan. International Journal of Innovation in Language Learning and Teaching, 1(1), 153-174.

Cohen, G., Steele, C., and Ross, L. (1999).
The mentor's dilemma: Providing critical feedback across the racial divide. Personality and Social Psychology Bulletin, 25(10), 13021318.

Dulay, H., Burt, M., and Krashen, S. (1982). Language Two, Oxford University Press, New York.

Espinosa, D. (2017). Vlogging Through Virtual Lessons: Enhancing Speaking Skills on a EFL Blended Learning Environment. Universidad Externado de Colombia. Non-published thesis article.

Flege, J. (1995). Second-language speech learning: Theory, findings and problems", in STRANGE, W. (Ed.) Speech Perception and Linguistic Experience: Theoretical and Methodological Issues in Cross-Language Speech Research. Timonium, MD: York

Freeman, R. E. (1999). Divergent stakeholder theory. Academy of management review, 24(2), 233-236.

Hattie, J. and Timperley, H. (2007) The Power of Feedback. Review of Educational Research, 77 (1), 81-112.

Hattie, J. (2003). Teachers Make a Difference, what is the research evidence?

Hyland, K., and Hyland, F. (2006). Feedback on second language students' writing. Language teaching, 39(02), 83-101.

Ismail, J. (1991). Language exposure and second language learning. The English Teacher, 20, 20-31. 
Ivanic, R., Clark, R. and Rimmershaw, R. (2000). What am I supposed to make of this? The messages conveyed to students by tutors' written comments. In M.R.

Jungmi, K. (2003). A Study of negotiation of meaning in NNS-NNS interactions - focusing on synchronous CMC. Paper presented at the 8th conference of Pan-Pacific Association of Applied Linguistics. Japan.

Ketsman, O. (2012). Expectations in the foreign language classrooms: A case study. The Qualitative Report, 17(53), 1.

Kraback, A. (2014). Developmental feedback. California State University. Retrieved from: https://www.csustan. edu/writing-center/faculty-information/developmental-feedback

Kumaravadivelu, B. (1986). Second Languages: a cross-linguistic perspective. Applied Psycholinguistics, 7(2), 157.

Loewen, S. (2012). The role of feedback. The Routledge handbook of second language acquisition, 442-460.

Lightbown, P., and Spada, N. (2006). How languages are learned. Oxford University Press.

Lyster, R. (2002). Negotiation in immersion teacher-student integration. Educational research. Department of Integrated Studies in Education, McGill University found it on: http:/ / personnel.mcgill.ca/files/roy.lyster/ Lyster2002_IJER.pdf

Nicol, D. and Macfarlane-Dick, D. (2006) Formativeassessmentandself-regulated learning: a model and seven principles of good feedback practice. Studies in Higher Education. 31 (2), 2006. DOI: 10.1080/03075070600572090.

Poulos, A. and Mahony, M. J. (2008). Effectiveness of feedback: The students' perspective. Assessment $\mathcal{E}$ Evaluation in Higher Education, 33(2), 143-154.

Sadler, D. (1989). Formative assessment and the design of instructional systems. Instructional science, 18(2), 119144.

Sadler, D. (2010). Beyond feedback: Developing student capability in complex appraisal. Assessment and Evaluation in Higher Education, 35(5), 535550.

Tomlinson, B. (2012). State-of-the-art article: Materials development for language learning and teaching. Language Teaching, 45(2), 143-179.

William, M. and Burden, R., 2009. Psychology for language teachers: a social constructivist approach. Cambridge: Cambridge University Press.

Willis, J. (1996). A flexible framework for task-based learning. Challenge and change in language teaching, 52-62.

Yin, R. (1994). Case Study Research: Design and methods. California, United States.

Yin, R. (2003). Case Study Research: Design and methods. California, United States

Yin, R. (2012). Case Study Methods. American Psychological Association. Washington DC, United States. 
Yorke, M. (2003). Formative assessment in higher education: Moves towards theory and the enhancement of pedagogic practice. Higher education, 45(4), 477-501.

Zimmerman, B. (1989). Models of selfregulated learning and academic achievement. In Self-regulated learning and academic achievement. Springer New York.

Zainal, Z. (2007). Case study as a research method. Jurnal Kemanusiaan, (9), 1-6. 